\title{
Stakeholder perspectives on citation and peer-based rankings of higher education journals
}

\author{
Stephen Wilkins ${ }^{a}$ and Jeroen Huisman ${ }^{b}$ \\ ${ }^{a}$ Graduate School of Management, Plymouth University, Plymouth, UK; ${ }^{b}$ Department of Sociology, \\ Faculty of Political and Social Sciences, University of Ghent, Ghent, Belgium.
}

The purpose of this article is to identify and discuss the possible uses of higher education journal rankings and the associated advantages and disadvantages of using them. The research involved 40 individuals - such as lecturers, university managers, journal editors and publishers - who represented a range of stakeholders involved with the research of higher education. The respondents completed an online questionnaire that consisted mainly of open questions. Although the respondents indicating clear support or opposition to journal rankings were split about equally, over two-thirds of the respondents reported having used or referred to a journal ranking during the previous 12 months. This suggests wide acceptance of the use of journal rankings, despite the fact that the downsides and problematic nature of these rankings were clearly recognised. It raises the question why the very diverse field of higher education does not show more resistance against the rather homogenising instrument of journal rankings.

Keywords: higher education journals; journal quality; journal rankings; journal lists; citation analysis

\section{Introduction}

Over the last decade, academic journals have undoubtedly become the most popular and influential form of publishing for the dissemination of research on higher education. Although much higher education research is still published as monographs and as grey literature, academic journals are increasingly regarded as the natural and most prestigious outlet for high quality academic research. The peer review process and low acceptance rates of journals are widely seen as indicators of quality assurance (Goodyear et al., 2009). The use of the Internet and the bundled subscriptions of universities to the journals of the largest publishing houses have resulted in journals often being far more accessible to researchers and students worldwide compared to other forms of publishing.

In many countries globally, the formal and systematic assessment of research outcomes has been considered an instrument of New Public Management (Deem, 2001; Togia \& Tsigilis, 2006; Wilmott, 1995). In this context, it is argued that institutional managers and governments have become obsessed with research quality even though there is little consensus on what constitutes quality research and how it can be recognised (Nedeva, Boden, \& Nugroho, 2012). In some fields of research, such as business and medicine, those responsible for assessing research quality have increasingly turned to journal rankings and quality lists for guidance. Information about the status of higher education journals can influence where researchers choose to publish and which journals they choose to read and how the assessors of research quality determine their outcomes (Bray \& Major, 2011). 
Wilkins, S. and Huisman, J. (2015). Stakeholder perspectives on citation and peer-based rankings of higher education journals. Tertiary Education and Management, 21(1), 1-15.

We nevertheless do not know much about how journal rankings are perceived in the field of higher education. The purpose of this article is to identify and discuss the possible uses of higher education journal rankings and the associated advantages and disadvantages of using them. In this explorative article we use the term 'journal ranking' to include all types of publication that attempt to rate academic journals, which includes peer reviewed quality guides and journal citation reports.

In the following section we consider the features of high quality research and high quality journals, the different types of ranking that exist as well as how the different rankings are compiled. We follow these sections with a review of the literature on journal rankings in the higher education and broader education fields. Then, after we have given details about our method, we identify and discuss possible advantages and disadvantages of using journal rankings, which incorporates the views and opinions of a range of relevant stakeholders, such as authors, university managers, funders of research, editors and publishers. The quotes included in the article were obtained from a survey that utilised a self-completed online questionnaire. We conclude with a section that summarises our respondents' overall attitudes toward journal rankings and discusses possible implications of journal rankings on higher education research in the future.

\section{Journal rankings \\ Judging research quality}

It may not seem straightforward to agree on what high quality research is; views differ depending on the perspective the individual has. From the philosophy of sciences perspective, one may consider 'high-quality' research to meet the criterion of increasing our understanding of a certain phenomenon, but it needs to be noted that different theoretical and methodological approaches may meet that criterion (e.g. Popper's method of falsification versus Lakatos' research programmes versus Merton's middle range theories). From a methodology perspective there is obviously attention to issues of reliability and validity, methods being fit-for-purpose, etc. But also behind these generic labels there are a variety of criteria - sometimes conflicting - dependent on the (sub)discipline and dependent on whether one adheres to qualitative or quantitative research (see e.g. Denzin \& Lincoln, 2011 on qualitative research and Kaplan, 2004 on quantitative methods). Whereas the latter refer to social sciences in general, the myriad of approaches to and views on what is seen as 'quality' is reflected in volumes in the field of higher education that discuss methods (see e.g. Huisman \& Tight, 2013, 2014). Finally, from the perspective of the receivers of knowledge acquired through research, for instance policy-makers and practitioners, other criteria may be more important. The RAND Corporation (2014), for instance, includes in its standards for high quality research that "findings ... should bear on important policy issues" and that "the study should be ... relevant to stakeholders and decision makers". Despite these different approaches, we argue - for the purpose of this contribution - that high quality journals generally publish research that is original, rigorous in methodology and which makes a contribution to knowledge.

\section{Judging journal quality}

High quality journals ensure that they publish high quality research by implementing a rigorous peer review process that typically makes use of at least two reviewers. High quality or ' $A$ ' ranked - journals are universally recognised as such by the academic research community, which reads and cites relatively heavily the journals' articles. These journals 
Wilkins, S. and Huisman, J. (2015). Stakeholder perspectives on citation and peer-based rankings of higher education journals. Tertiary Education and Management, 21(1), 1-15.

achieve high citation impact factor scores, which confirm the journals' high status, and this attracts more high quality submissions. Thus, high quality journals find it relatively easy to maintain their elite status. As a result, editors of high quality journals can be very selective in what they publish and rejection rates are high. At higher education conferences held during 2012-13, the editors of several 'top' higher education journals reported acceptance rates of between $8-15 \%$.

' $A$ ' ranked journals are typically the target of established researchers, as they are expected by their peers, and likely by their managers, to publish in these journals, and doing so helps them to maintain their reputation and standing in the academic community. Authors who fail to get their articles accepted by the top ' $A$ ' ranking journals then send their work to the second-tier or ' $B$ ' ranking journals. We admit that we do not have precise insights into submission behaviour; it may be that many researchers have a good understanding of the quality of their work and target the most 'appropriate' journal straight away. Whatever the mechanisms, the point is that there is some understanding in the field of what top and second-tier journals are in the field of higher education (see e.g. Bray \& Major, 2011).

The second-tier journals typically have smaller readerships and often specialise in a specific sub-field of higher education research, such as policy, management or pedagogy, or they focus on authors and readers in a specific geographic region. These journals have lower citation impact factor scores than the top ' $A$ ' level journals and they also feature lower in peer reviewed quality rankings.

\section{Types of journal ranking}

Journal quality rankings and guides can be based on citation studies, such as the Thomson Reuters Journal Citations Reports (JCR); peer surveys (such as some lists prepared by universities); or they can be derived from other assessments or audits of research quality (such as official government audits). Some rankings use a mix of these methods. A few rankings and quality guides place journals into different hierarchical categories; for example, the Scopus SJR ranking divides its list into quartiles while the European Reference Index for the Humanities (ERIH), published by the European Science Foundation (ESF), allocates journals to one of three ranks: INT1 (international with high visibility); INT2 (international with significant visibility); and NAT (of significance in a particular European country).

The Social Sciences Citation Index (SCCl), published annually as the JCR lists, is the best known citation-based ranking internationally. The 2013 JCR for Education and Educational Research, published in July 2014, listed 219 journals from the many more that exist. The JCR list is dominated by English language journals that are published by the big international publishing houses based in the United States (US) and United Kingdom (UK). Not all journals that specialise in higher education research are included in the JCR reports; the 2013 report contains 15 journals that have 'higher education' in the journal title, whereas Research into Higher Education Abstracts (an authorative source when it comes to journals addressing higher education) lists 38 journals with 'higher education' in the title and many more that explicitly refer to post-secondary education.

The fact that Research into Higher Education Abstracts' full list of journals publishing articles on higher education (more than 300 journals) is already much longer than the JCR education list (219 in the latest edition) is another illustration of JCR's restrictiveness. This severely limits the usefulness of the JCR reports to higher education researchers, especially new career researchers who may want information on other than the 'top' journals, to aid their decision making on where to publish. Impact factors are biased towards certain types of 
Wilkins, S. and Huisman, J. (2015). Stakeholder perspectives on citation and peer-based rankings of higher education journals. Tertiary Education and Management, 21(1), 1-15.

journals and articles, for example, quantitative studies and review articles. It has been estimated that half of the articles published in a journal typically account for $90 \%$ of the journal's citations (Seglen, 1997).

The methodology of the JCR has been widely criticised (Togia \& Tsigilis, 2006). The impact factor of a journal is calculated by dividing the total number of citations received in the JCR year by the total number of articles published in the previous two years. Thus, an impact factor of 1 means that, on average, the articles published one or two years ago have been cited once. The two-year citation period has been criticised as arbitrary and too short given the long manuscript acceptance to publication times nowadays (Aguillo, 1996; Bloch \& Walter, 2001; Togia \& Tsigilis, 2006). It is assumed that receiving a citation is a positive thing, but a citation that is negative and which actually criticises a study, still counts towards citation numbers. Also, impact factors can be influenced or even manipulated by authors and publishers in a number of ways, for example through self-citation and putting new articles online several months before their official publication date. Finally, it should be noted that a great deal of higher education research is published as monographs (books, reports etc.) and references to these in journal articles are usually missed in calculating the impact factor scores.

The JCR list is very selective and journals have to meet a range of criteria before they will even be considered for inclusion in the list. New journals typically need to have been in existence for over six years before they can be included in the list. Not having an $\mathrm{SSCl}$ impact factor makes it harder for new, younger and potentially more innovative journals to grow readerships and submission levels. This acts as a constraint on the development of higher education as a scholarly field and with it the development of theory and new lines of inquiry. The privileged journals that are ranked highly on journal lists are typically generalist and conservative, and they publish widely researched topics using particular favoured methodologies and traditions (Hutchinson \& Lovell, 2004; Tight, 2012b; Willmott, 2011). Thus, it can be argued that journal rankings - and the JCR list in particular, with its selected coverage of titles - exert a homogenising effect upon research culture (Willmott, 2011).

An alternative to the $\mathrm{SSCl}$ is the SCImago Journal Rank index (SJR), which has been part of Elsevier's Scopus database since 1996. The SJR indicator was developed on the assumption that not all citations are equal and thus it assigns different values to citations based on the importance of the journals where they came from. The complex algorithm that the SJR index uses is not easily understood by researchers or those that must assess research quality. Although users and potential users may believe there exists a lack of transparency in how the SJR index is calculated, an advantage of the index over the $\mathrm{SSCl}$ is that in 2013 it listed 1,035 education journals, giving it a much wider coverage of journals in the field.

In 2010, the Australian Research Council (ARC) published an academic journal ranking, which was updated in 2012, that was to be used in the Excellence in Research for Australia (ERA) assessment of research quality in Australia. The ranking was in the end not used in the 2012 ERA and it was announced by the government that institutions had used the rankings in ways not originally intended, including gamesmanship to boost research ratings and the performance management of staff (Dobson, 2014).

This section has demonstrated that there are different types of ranking that can be used by stakeholders who wish to gain information on journal and research quality. The different rankings might each have their own set of advantages and disadvantages against the others, so this study seeks to ascertain whether various stakeholders make use of journal rankings, which rankings are used most and the reasons why. 
Wilkins, S. and Huisman, J. (2015). Stakeholder perspectives on citation and peer-based rankings of higher education journals. Tertiary Education and Management, 21(1), 1-15.

\section{Research on journal rankings}

The literature on journal rankings in the field is very limited; we were only able to retrieve a few papers on education journals in general (e.g. Goodyear et al., 2009; Hardy, Heimans, \& Lingard, 2011; Togia \& Tsigili, 2006) and only one on higher education specifically (Bray \& Major, 2011). Much of the research on journal rankings is carried out in other disciplines (e.g. Hudson, 2013; Nedeva, Boden, \& Nugroho, 2012; Willmott, 2011).

University managers are increasingly referring to journal ranking lists when evaluating the research quality of their subordinates because it saves them time, as they do not have to actually read the articles; they lack the subject expertise to make objective evaluations themselves; it can be used as an indicator to demonstrate improved institution or department research output; and it can be seen as a relatively fair and transparent method of determining research quality (Nedeva, Boden, \& Nugroho, 2012). However, it is a fact that the 'top' journals occasionally publish research that is not of top quality and that lower ranked journals often publish high quality work (Oswald, 2007). The existence of journal lists encourages assessors of research quality to not spend time on critical reading and to rely instead on where journals are placed in the lists. The danger is that university managers and external assessors of research quality award lower grades or levels to high quality articles simply because they are published in lower ranked journals (Willmott, 2011).

In recent years, more governments globally have decided to undertake periodic audits of research quality, such as the ERA in Australia and the Research Excellence Framework (REF) in the UK. There exists considerable debate about whether such assessments should be based on bibliometrics (typically citation scores), peer review, and/or (non-academic) impact (Brinn, Jones, \& Pendlebury, 2000; Butler \& McAllister, 2009; Campanario, 1998; Moed, Luwel, \& Nederhof, 2002; Pontille \& Torny, 2010). Bibliometrics may be seen as objective and relatively simple to produce whereas peer review is subjective and takes longer to perform. Societal impact is important, but difficult to measure. However, 'top' journals do sometimes publish weaker articles and lower ranked journals often publish high quality work, so it is only by reading individual articles that quality can be accurately assessed.

Journal rankings, as a tool of New Public Management, are widely seen as a political instrument and tool for management control rather than as a tool to encourage scholarly inquiry and the generation of higher quality research outputs (Wilmott, 1995, 2011). For many stakeholders involved with the research of higher education, rankings have become a fact of life that cannot be ignored. Previous research has concluded that getting published in high ranked journals is critical to faculty appointments, promotions and salary increases (Bray \& Major, 2011; Davis \& Astin, 1987; Nelson, Buss, \& Katzko, 1983; O’Neill \& Sachis, 1994).

Citation-based journal rankings, as their name suggests, detail the citation rates of journals, yet in the higher education field, much research is published as monographs. If you look at the top higher education scholars, you will typically find that their top cited work is in the form of books, not journal articles. For example, Simon Marginson's work has attracted over 10,500 citations (at the end of 2014), but his top three citations are books. If citations are important in determining research quality, then it does not make sense to ignore books in citation-based rankings (see also Tight, 2009, who analysed citation patterns in seventeen higher education journals and found that $56 \%$ of the citations were books and reports). Nevertheless, researchers of higher education may sometimes find it useful to refer to rankings in the course of their research; for example Tight's study on levels of analysis in 
Wilkins, S. and Huisman, J. (2015). Stakeholder perspectives on citation and peer-based rankings of higher education journals. Tertiary Education and Management, 21(1), 1-15.

higher education research (2012a) considered three rankings to ensure that the study included the journals that are 'both well-established and of the highest status'.

Much higher education research is conducted outside education departments (Tight, 2012b). Researchers in non-education departments are commonly forced to work with rankings specific to disciplines that are not education. For example, nearly all of the leading Business Schools in the UK use the Academic Journal Quality Guide of the Association of Business Schools (ABS) (Wells, 2010). The ABS guide includes only seven journals that are dedicated to higher education, and of these only one (Studies in Higher Education) is categorised at grade three and there are none at grade four (the highest grade). Grade three is the minimum level expected of high quality researchers, for example, those wanting to be included in the REF research assessment exercise. The result is that research active staff in business schools, researching, say, management, marketing or quality in higher education, find it difficult to gain promotion and salary increases because their particular specialism has no journals at a particular level on a particular list, and hence there exists a risk that their career comes to a halt.

Higher education journals tend to have lower citation levels than the journals in many other fields. This may be because a high proportion of higher education research is published and cited in books and the grey literature, such as policy reports. Another contributing factor is the fact that the North American journals are strongly dominated by North American authors writing about topics often specific to North America - which are then read mainly by a North American audience - which has resulted in the existence of two separate higher education research communities divided by North American/non-North American location (Tight, 2007; Tight 2012b). This is somewhat surprising since it is customary in the social sciences to claim scholarly achievement when a concept or phenomenon crosses national borders; hence, researchers generally seek international impact (Özbilgin, 2009). Although we do not have empirical support for this, the small size of the higher education field may also play a role in the lower citation levels.

Rumbley, Stanfield, \& de Gayardon (2014) found that the four most popular languages used in higher education journals are English (190 journals), Chinese (27), Japanese (26) and Spanish (15), and that nearly half of all higher education journals are published in the US or UK. As all of the best-known journal rankings are dominated by English-language journals published predominantly by the big publishing houses located in North America, West Europe and Australia, these rankings often have less value and relevance to researchers in other regions of the world.

Although there is limited research on journal rankings in the education field, it is clear from the literature that does exist, that rankings and journal quality guides may have a range of limitations and weaknesses. This research is interested in discovering the extent to which a range of stakeholders involved with the research of higher education are aware of these potential limitations and weaknesses, and the extent to which they influence the stakeholders' opinions and attitudes toward journal rankings and quality lists.

\section{Method}

The research involved 40 individuals, who represented a range of stakeholders involved with the research of higher education. Respondents completed an online questionnaire, administered in July-August 2014, that consisted mainly of open questions, which were designed to gain information about the respondents' actions, opinions and attitudes, without influencing the content of their answers. A convenience sampling strategy was adopted; 60 
Wilkins, S. and Huisman, J. (2015). Stakeholder perspectives on citation and peer-based rankings of higher education journals. Tertiary Education and Management, 21(1), 1-15.

questionnaires were sent out by email, and as 40 were completed, the response rate was $66.7 \%$. Table 1 provides a summary profile of the respondents and Appendix 1 gives details about the items used in the questionnaire. A rigorous process of thematic analysis was undertaken to identify ideas, patterns and relationships in the data, which involved phases of data familiarisation, coding, searching for themes among the codes, and definition of the themes. We considered using a data analysis tool such as the NVivo program, but finally decided that these were not necessary given the relative simplicity and straightforwardness of our questionnaire and the data obtained.

Table 1. Summary profile of respondents $(n=40)$.

\begin{tabular}{lr} 
Sex & \\
Male & 28 \\
Female & 12 \\
Main job role & 24 \\
$\quad$ Lecturer/Researcher/Author & 2 \\
Manager in higher education institution with responsibility for assessing & \\
$\quad$ research quality & 2 \\
Journal editor & 3 \\
Publisher & 9 \\
Other, including higher education administrator, funder of research, and & \\
$\quad$ government organisation responsible for assessing research quality & \\
Rank if working as an academic & 11 \\
Lecturer/Instructor (or equivalent) & 9 \\
Associate professor/Senior lecturer (or equivalent) & 11 \\
Professor/Reader (or equivalent) & \\
Region in which worked most during the last five years & 5 \\
Asia & 3 \\
Australasia & 24 \\
Europe & 8 \\
North America & \\
\hline
\end{tabular}

Note: ${ }^{\text {T}}$ Three further journal editors classified their main job role as lecturer/researcher/author

\section{Findings}

\section{Reasons for using journal rankings}

Journal rankings and journal quality guides are intended to indicate to users the likely quality of the articles each journal publishes. Many of our respondents felt that journal rankings and journal quality guides may be useful as an information source for researchers on where best to publish their work. Some respondents suggested that this might be particularly important for early career researchers who may not yet be familiar with the journals in their field and the relative standing between journals, and so rankings can help them decide which journals to read and where to publish. Other respondents argued that rankings might also benefit researchers undertaking interdisciplinary research that crosses into fields in which they have less experience of publishing as well as very experienced researchers who want to monitor publishing trends to ensure that they are reading and publishing in the best journals possible. 
Wilkins, S. and Huisman, J. (2015). Stakeholder perspectives on citation and peer-based rankings of higher education journals. Tertiary Education and Management, 21(1), 1-15.

I use lists to assess the rankings of journals where I am considering an article submission and to see the ranking of journals where I have already published. (Administrator at a research university, US)

I refer to the journal list to see if a journal unknown to me is 'serious'. (Associate professor, Netherlands)

In my experience, the journal impact rank in very broad lines does give an indication of the general quality of the articles published. It is informative to orient on the landscape of journals, particularly when entering a somewhat newer field or for entering researchers. (Associate professor, Netherlands)

Some respondents see rankings as meaningful certification of scholarly achievement. Rankings provide some researchers with a challenge because the benefits of publishing in the top journals - prestige and enhancement of personal reputations - can be a major source of satisfaction. However, our results suggest that the majority of users refer to rankings because they feel they have to, as the rankings are used and relied upon by other important stakeholders such as employers and funders of research.

I refer to journal rankings to make sure that I send my articles to esteemed journals that will be recognised by my employer. (Lecturer, UK)

I need to report the impact factor of the journals I've published in for my performance review, so a relative list is helpful to put this in the context. (Associate professor, Netherlands)

For academics who are fortunate to publish in high-ranking journals, it can positively influence their professional advancement - tenure and promotion - and colleagues may respect these rankings. (Administrator at a research university, US)

\section{A helpful and transparent instrument}

Some respondents argued that journal rankings are helpful and, particularly in the case of citation-based rankings, that their methodology is transparent and logical. We found that journal rankings are used by a range of stakeholders involved with the research of higher education, including journal editors, publishers and research funding organisations.

Despite their shortcomings, bibliometrics such as the Impact Factor are easily understood and remain the best guide to a journal and/or an author's influence or impact in its/their field. (Publisher, UK)

As an editor of a journal, I was provided with the results of the ranking for my journal as part of the regular materials our publisher provides with regard to the status and 'performance' of the publication. This kind of information so far is giving me a sense of trends (are we rising or falling in these rankings) and provides me with food for thought about what might be the cause of these developments. I think a journal ranking can provide incentives to think more deeply about performance. This does not mean one should perform 'for' the rankings, but rather one can use the ranking information as one 
Wilkins, S. and Huisman, J. (2015). Stakeholder perspectives on citation and peer-based rankings of higher education journals. Tertiary Education and Management, 21(1), 1-15.

piece of a broader menu of information to help determine trends, possibilities, challenges, etc. This can be helpful for strategic planning. (Journal editor, US)

Rankings give me a picture of how our journals are performing compared to others and they give indicators on how to improve a journal's performance. (Publisher, Netherlands)

\section{Arbitrary decisions?}

Several of our respondents have experience of universities or research funding organisations taking seemingly arbitrary decisions such as recognising only research published in journals that are listed in the JCR or Scopus SJR lists.

In some fields or disciplines it is clear that certain journals carry greater weight. This is not yet so clear in the field of higher education research. If that were the case, it would make exercises such as the UK REF easier and less time consuming. I also edit two journals, so I am interested in how they rate. (Professor and journal editor, UK)

I need an overview of the higher education journals that are listed in ISI [the SCCI index/JCR reports] and Scopus, including their order. However, it must be emphasised that this is mainly due to the peculiar design of the Czech research policy that does not acknowledge journal publications outside ISI or Scopus. (Lecturer, Czech Republic)

\section{Users' choice of journal rankings}

Twenty-seven of our respondents (67.5\%) had used or referred to the SCCI index, published in the JCR reports, during the previous 12 months. The next most popular ranking was the Scopus SJR index, which was used by fifteen respondents (37.5\%). All users of the Scopus SJR index had also used the SCCI index/JCR reports. The Australian Research Council's (ARC) list was used by five respondents and the European ERIH list was used by only three respondents. Most users of the JCR reports said that they had chosen this ranking over others because it was the most well-known and widely used and also the ranking used by colleagues and managers.

ISI [the SCCI index/JCR reports] is the standard. (Publisher, Netherlands)

I use Thomson Reuters Impact factor [the SSCI index/JCR reports] primarily because it is the most prestigious and most used. (Professor, Australia)

I use mainly the JCR ranking because it is the best known and our managers use it to assess our research, but I also look at Scopus as it lists many more journals than the JCR list. (Lecturer, UK)

\section{Perceived disadvantages and problems with journal rankings}

Some of our respondents appear to feel coerced into using rankings, even though their limitations and weaknesses are well-known and understood. Some respondents reported feeling pressured into sending their articles to journals in the JCR list and to those with high positions in rankings rather than to the journals that are more appropriate in terms of subject coverage and readership. This has led to some of the top journals having very high submission rates while journals lower down the rankings run short of submissions of acceptable quality. 
Wilkins, S. and Huisman, J. (2015). Stakeholder perspectives on citation and peer-based rankings of higher education journals. Tertiary Education and Management, 21(1), 1-15.

In this way, rankings have become a self-fulfilling prophecy, as the higher ranked journals attract the higher quality articles, which then achieve higher impact factors for the journals as well as attracting larger readerships, and this then encourages more high quality submissions. Several respondents addressed the lack of attention to the quality of individual contributions.

I must use the ISI [the SCCI index/JCR reports] because, in my performance review, articles published in ISI-listed journals carry double weighting to those that are not in the list. (Associate professor, Lithuania)

It seems to me that the publication outlet has become more important than the content and contribution of the research, and this is beginning to impede the development of higher education research. Many researchers (not me!) are desperate to get published in the so-called 'top' journals while good journals lower in the rankings are often struggling to attract submissions. (Lecturer, UK)

It is by no means clear that 'top' journals only publish articles of 'top' quality; that is to say, there is a danger that scholars are evaluated by the assumed quality of the journals in which they publish rather than by the quality of the content of their research publications. (Associate professor, Germany)

The danger of focusing too much on quantitative information is missing other indicators for the quality of the work. (Funder of research, Netherlands)

\section{Coverage of journal lists}

Several respondents complained about the narrow range of titles in the JCR list, while others observed that many of the 'top' journals were only interested in research on a narrow range of topics that employed particular methodologies. A likely result of researchers feeling pressured to send their articles to journals that are listed in the rankings is that they may avoid the journals that are excluded from the rankings.

The coverage of these lists, particularly Thomson Reuters' $\mathrm{SSCl}$, is often too limited to be representative of the field and Scopus' SJR indicator may be too complicated for authors to understand. (Publisher, UK)

Rankings might curtail innovation and creativity in the field, in that to get published in a highly ranked journal generally means subscribing to its ethos. In higher education, this is very apparent. (Associate professor, Australia)

I would really like to support a new journal like $X X X X$ [name of journal anonymised] but am discouraged from doing so because the journal is not, I think, widely recognised internationally yet, and not having an impact factor means that publishing in this journal will count for little in my performance review. (Associate professor, Lithuania)

A couple of respondents argued that journal rankings encouraged university managers and funders of research to view less positively research published in other outlets and forms. 
Wilkins, S. and Huisman, J. (2015). Stakeholder perspectives on citation and peer-based rankings of higher education journals. Tertiary Education and Management, 21(1), 1-15.

With the emphasis on journals, we forget the thriving community in print publications, which publishes good books on higher education. An example is the National Higher Education Research Institute in Malaysia which has published many good books on higher education, in particular from the perspectives of developing countries. These books reach a greater audience, whereas pay walled journals reach only subscribers. For higher education researchers to influence policy makers, the former has greater impact. (Doctoral student, Malaysia)

\section{Higher education as an interdisciplinary and heterogeneous field}

The data provided by our respondents suggests that journal rankings might have a particularly negative influence upon higher education researchers working in interdisciplinary contexts. University managers working outside education departments typically have limited, or no, knowledge of the specialist higher education journals that exist, and as a result the quality of work achieved by interdisciplinary researchers may go unrecognised and unrewarded.

Some respondents working in non-Anglophone countries argued that the most popular journal rankings were (wrongly) biased towards English language journals and publishers, and that often the rankings were irrelevant anyway given that most of the research they published was in their own national language.

As a higher education researcher in a management school it is very hard because many of my research outputs are not really recognised or valued in my university because they are not published in journals on the ABS list. Also, my colleagues publishing in other fields are able to gain much higher impact, and consequently higher education research is regarded as an easy option that is less prestigious (Lecturer, UK)

Lots of journals that make the lists are published in particular countries like the UK, US and Australia, as well as other EU [European Union] countries. Higher education research in the Asia Pacific region is thriving as well, especially in Hong Kong and Singapore. I think journals from the Asia Pacific need boosting up as well. (PhD student, Malaysia)

I have never used journal rankings, and although many university professors in Japan do understand the value of rankings, they are of little relevance because they only write papers in the Japanese language. (Higher education practitioner, Japan)

\section{Overall attitudes toward journal rankings}

Our respondents indicated that many stakeholders seem to accept that perceived journal quality has become a common proxy for the quality of an individual article. Our results suggest that journal rankings might have both benefits and drawbacks for the higher education research community. Some respondents were in favour of rankings while others were fervently against or opposed to them. The respondents indicating clear support or opposition to journal rankings were split about equally while a number of respondents took neutral positions or replied that they were undecided or not sure.

On balance, I am in favour of journal rankings. At a time when we are awash with information, there have to be recognised, authoritative sources of information for the author. However, they should not be taken at face value. (Publisher, UK) 
Wilkins, S. and Huisman, J. (2015). Stakeholder perspectives on citation and peer-based rankings of higher education journals. Tertiary Education and Management, 21(1), 1-15.

I am in favour of using journal rankings in building someone's case for tenure or promotion, scholarly awards, and in the selection of membership to academies such as AERA (American Educational Research Association) Fellows. (Professor, US)

In general, I am against them because they reduce issues of quality. Indeed, they miss aspects of quality. They create a hierarchy built on a false premise. In the end, they are control mechanisms. (Professor, Australia)

I am more against rankings as they, especially ISI [the SCCI index/JCR reports] perpetuate the notion of 4-5 'top' higher education journals but without convincing evidence to me. Citations should not be the only criterion! However, realistically, some rankings will always be there, so I would suggest improving the existing ones on data collection and utilisation. (Lecturer, Czech Republic)

Two respondents were not familiar with rankings. One of these was a doctoral student. It is clear that some doctoral schools 'educate' students about rankings, while others do not. Given that publication in the high ranked journals is likely to be a key driver of future career advancement, it could be argued that students should at least be encouraged to consider rankings.

I don't use rankings, so I don't know what the potential advantages or disadvantages would be. I don't seek out a journal based on rankings, but on the readership of the journal and/or the target audience. (Doctoral student, US)

We need to publish as part of the requirements for PhD. There are two options: publish in journals with no impact factor, as the easy way out, or hit high and publish in refereed journals with an impact factor, as an indicator on the quality of the publication. The list of higher education journals is a good start on where to publish for PhD students that are aiming high. (Doctoral student, Malaysia)

Respondents both in favour and against journal rankings seemed to agree that rankings are here to stay. Many respondents said that it could be useful to refer to journal rankings but that it should be done with care and appreciation of the potential dangers and drawbacks.

It's okay to use rankings but be aware that there are other means of determining the quality and relevance of a journal to your field of study. (Publisher, UK)

Whether or not you use or ignore rankings depends on where you are placed in the higher education sector. If you are lowly ranked, you don't have a choice but to take notice of them - but users should be aware of the rankings' limitations. (Professor, Australia)

I have mixed feelings about rankings, but it doesn't really matter what I think; they're here to stay. (Professor, UK)

\section{Conclusion}

Rankings have become an established part of the academic publishing landscape, as recognised by almost all of our respondents. The survey revealed that the majority of 
Wilkins, S. and Huisman, J. (2015). Stakeholder perspectives on citation and peer-based rankings of higher education journals. Tertiary Education and Management, 21(1), 1-15.

individuals involved with the research of higher education have used or referred to at least one journal ranking or journal quality list in the last 12 months.

The JCR list is by far the most well-known and used, followed by Scopus SJR. Love them or hate them, researchers, editors and publishers with some sense of self-preservation seem to recognise the 'rules of the game' and act accordingly in order to realise their objectives and ambitions. A scholar who refuses to publish in the top ranking journals is less likely to gain tenure and promotion and journal editors who shun rankings and keep their journals off the lists are likely to be missing out on high quality submissions that are sent elsewhere, which could lead to a downward spiral of lower quality submissions/publications, lower citations and lower readerships. Thus, playing the rankings game has become an arena for individuals to construct a favourable identity and maintain their self-esteem (Nkomo, 2009).

It should be noted that the pressure to recognise or use journal rankings was not felt evenly across our respondents. Our sample size was too small to find meaningful and reliable patterns (e.g. new versus established scholars; countries or regions strongly influenced by New Public Management ideologies versus others; researchers versus practitioners), but it was interesting to see that some respondents were very much abreast of the ins and outs of journal rankings, whereas some hardly knew about their existence.

What we found the most striking finding is the lack of resistance against journal rankings. The higher education research field is very heterogeneous in many respects, e.g. regarding the vehicles for disseminating new knowledge (books, reports etc., with journals being only one of them), the interdisciplinary nature of our research, and the fact that much of our research is practice-and policy-oriented. Given this heterogeneity, we expected to see many more concerns about the rather restrictive take on quality (equated by high journal citations) espoused by journal rankings. Does our analysis imply that journal rankings - the analogy with university rankings lies at hand - are such strong instruments, that resistance is actually in vain?

Our investigation was explorative, and further research must be carried out to reveal how journal rankings impact upon the publishing behaviour of higher education researchers and whether this has detrimental effects on how our field progresses. At the same time, we argue that researchers in higher education should not take journal rankings as a fact of life. The positive elements of rankings can be preserved (particularly transparency), but researchers must continue to search for better indicators that reflect the diversity of our field of research.

If one were to accept the relevance of citations, an alternative to journal rankings might be the $h$ index. This index was suggested by Jorge Hirsch in 2005. The $h$ index attempts to measure both the productivity and impact of a researcher. The $h$ index is the largest number $h$, such that $h$ publications have at least $h$ citations. So, if a scholar has an $h$ index of 12 , it means that he/she has 12 papers that have at least 12 citations each. The $h$ index's popularity has been boosted through its use by Google Scholar. The $h$ index ignores where an article has been published, so journal positions in rankings become irrelevant. If citation-based rankings are compiled on the basis that it is citations that are the key indicator of research quality, then such rankings would appear to have been made obsolete by the $\mathrm{h}$ index and similar citation-based indicators. The $h$ index does have its own weaknesses however and Barnes (2014) argues that the $h$ index is "intrinsically meaningless" and criticises the use of the $h$ index as an aid to decision-making in the higher education sector, but in light of our investigation it may form a healthy antidote - even if it were temporary - for the preoccupation with journal rankings. 
Wilkins, S. and Huisman, J. (2015). Stakeholder perspectives on citation and peer-based rankings of higher education journals. Tertiary Education and Management, 21(1), 1-15.

We think however, that a focus on alternative measures is not enough. We found it alarming to find so many shortcomings and unwanted side-effects reported in the literature, although these mostly pertained to other disciplines rather than the higher education field. We see evidence for the hypothesis that journal rankings suppress interdisciplinarity (e.g. Rafols et al., 2012) and support for the claim that journal rankings stifle innovation (Nedeva, Boden, \& Nugroho, 2012; Willmott, 2011). Particularly in a highly diversified and interdisciplinary field like higher education research (in terms of research themes, methods, epistemologies, but also with respect to audiences, readership and outlets), preserving this diversity may be as important as looking for measures that could be used as proxies for quality. In light of the (potential) detrimental harms of journal rankings, we suggest it would be advantageous to first get a better insight into researchers' publication behaviour and its effects before we accept journal rankings. In some other fields (notably in the sciences), resistance to the 'tyranny of citation impact' has led to the launch of the San Francisco Declaration on Research Assessment (DORA), arguing for better ways to evaluate research outputs. We do not necessarily call for a similar initiative, but would suggest that higher education researchers be much more introspective and critically investigate the pros and cons of citations and journal rankings in our field.

\section{References}

Aguillo, I. F. (1996). Increasing the between-year stability of the impact factor in the Science Citation Index. Scientometrics, 35(2), 279-282.

Barnes, C. (2014). The emperor's new clothes: The h-index as a guide to resource allocation in higher education. Journal of Higher Education Policy and Management, 36(5), 456-470.

Bloch, S., \& Walter, G. (2001). The impact factor: Time for change. Australian and New Zealand Journal of Psychiatry, 35(5), 563-568.

Bray, N. J., \& Major, C. H. (2011). Status of journals in the field of higher education. Journal of Higher Education, 82(4), 479-503.

Brinn, T., Jones, M. J., \& Pendlebury, M. (2000). Measuring research quality: Peer review 1, citation indices 0. Omega, 28(2), 237-239.

Butler, L., \& McAllister, I. (2009). Metrics or peer review? Evaluating the 2001 UK Research Assessment Exercise in Political Science. Political Studies Review, 7(1), 3-17.

Campanario, J. M. (1998). Peer review for journals as it stands today - Part 1. Science Communication, 19(3), 181-211.

Davis, D. E., \& Astin, H. S. (1987). Reputational standing in academe. Journal of Higher Education, 58(3), 261-275.

Deem, R. (2001). Globalisation, new managerialism, academic capitalism and entrepreneurialism in universities: Is the local dimension still important? Comparative Education, 37(1), 7-20.

Denzin, N. K., \& Lincoln, Y. S. (Eds.). (2011). The Sage handbook of qualitative research. Thousand Oaks, CA: SAGE.

Dobson, I. R. (2014). Using data and experts to make the wrong decision: The rise and fall of journal ranking in Australia. In M. E. Menon, D. G. Terkla, \& P. Gibbs (Eds.), Using data to improve higher education: Research, policy and Practice. (pp. 229-242). Rotterdam: Sense Publishers.

Goodyear, R. K., Brewer, D. J., Gallagher, K. S., Tracey, T. J. G., Claiborn, C. D., Lichtenberg, J. W., \& Wampold, B. E. (2009). The intellectual foundations of education: Core journals and their impacts on scholarship and practice. Educational Researcher, 38(9), 700-706. 
Wilkins, S. and Huisman, J. (2015). Stakeholder perspectives on citation and peer-based rankings of higher education journals. Tertiary Education and Management, 21(1), 1-15.

Hardy, I., Heimans, S., \& Lingard, B. (2011). Journal Rankings: Positioning the field of educational research and educational academics. Power and Education, 3(1), 4-17.

Hudson, J. (2013). Ranking journals. The Economic Journal, 123(570), F202-F222.

Huisman J. \& Tight, M. (Eds.). (2013). Theory and method in higher education research, International perspectives in higher education research series, Vol. 9. Bingley: Emerald.

Huisman J. \& Tight, M. (Eds.). (2014). Theory and method in higher education research, International perspectives in higher education research series, Vol. 10. Bingley: Emerald.

Hutchinson, S. R., \& Lovell, C. D. (2004). A review of methodological characteristics of research published in key journals in higher education: Implications for graduate research training. Research in Higher Education, 45(4), 383-403.

Kaplan, D. (Ed.). (2004). The Sage handbook of quantitative methodology for the social sciences. Thousand Oaks, CA: SAGE.

Moed, H. F., Luwel, M., \& Nederhof, A. J. (2002). Towards research performance in the humanities. Library Trends, 50(3), 498-520.

Nedeva, M., Boden, R., \& Nugroho, Y. (2012). Rank and file: Managing individual performance in university research. Higher Education Policy, 25(3), 335-360.

Nelson, T. M., Buss, A. R., \& Katzko, M. (1983). Rating of scholarly journals by chairpersons in the social sciences. Research in Higher Education, 19(4), 469-497.

Nkomo, S. M. (2009). The seductive power of academic journal rankings: Challenges of searching for the otherwise. Academy of Management Learning and Education, 8(1), 106112.

O'Neill, G. P., \& Sachis, P. N. (1994). The importance of refereed publications in tenure and promotion decisions: A Canadian study. Higher Education, 28(4), 427-435.

Oswald, A. J. (2007). An examination of the reliability of prestigious scholarly journals: Evidence and implications for decision-makers. Economica, 74(293), 21-31.

Özbilgin, M. F. (2009). From journal rankings to making sense of the world. Academy of Management Learning and Education, 8(1), 113-121.

Pontille, D., \& Torny, D. (2010). The controversial policies of journal rankings: Evaluating social sciences and humanities. Research Evaluation, 19(5), 347-360.

Rafols, I., Leydesdorff, L., O'Hare, A., Nightingale, P., \& Stirling, A. (2012). How journal rankings can suppress interdisciplinary research: A comparison between Innovation Studies and Business \& Management. Research Policy, 41(7), 1262-1282.

RAND Corporation (2014). Standards for high-quality research and analysis. http://www.rand.org/standards/standards high.html (Accessed 18 September 2014).

Rumbley, L. E., Stanfield, D. A., \& de Gayardon, A. (2014). From inventory to insight: Making sense of the global landscape of higher education research, training, and publication. Studies in Higher Education, published online 1 September 2014, DOI: 10.1080/03075079.2014.949546.

Seglen, P. O. (1997). Why the impact factor of journals should not be used for evaluating research. British Medical Journal, 314(7079), 498-502.

Tight, M. (2007). Bridging the divide: A comparative analysis of articles in higher education journals published inside and outside North America. Higher Education, 53(2), 235-253.

Tight, M. (2009). The structure of academic research: What can citation studies tell us? In: A. Brew \& L. Lucas (Eds.), Academic research and researchers. Maidenhead: Open University Press \& McGraw-Hill, pp. 54-65

Tight, M. (2012a). Levels of analysis in higher education research. Tertiary Education and Management, 18(3), 271-288. 
Wilkins, S. and Huisman, J. (2015). Stakeholder perspectives on citation and peer-based rankings of higher education journals. Tertiary Education and Management, 21(1), 1-15.

Tight, M. (2012b). Researching Higher Education. Maidenhead: Open University Press/McGraw-Hill.

Togia, A., \& Tsigilis, D. (2006). Impact factor and education journals: A critical examination and analysis. International Journal of Educational Research, 45(6), 362-379.

Wells, P. (2010). The ABS rankings of journal quality: An exercise in delusion. Working paper. Cardiff: Centre for Business Relationships Accountability, Sustainability and Society.

Willmott, H. (1995). Managing the academics: Commodification and control in the development of university education in the U.K. Human Relations, 48(9), 993-1027.

Willmott, H. (2011). Journal list fetishism and the perversion of scholarship: Reactivity and the ABS list. Organization, 18(4), 429-442.

Appendix 1. Questionnaire items.

1. During the last 12 months, which of the following rankings have you used to assess journal quality? (multiple answers are possible)

- SSCl/Thomson Reuters Journal Citation Report (JCR) - previously ISI

- Scopus/SJR impact factor

- European Reference Index for the Humanities (ERIH), published by the European Science Foundation

- Australian Research Council (ARC)

- Other (please state name):

2. If you used or referred to a ranking or quality list of higher education journals during the last 12 months, please state the reason(s) why you used such a guide.

3. If you used or referred to a ranking or quality list of higher education journals during the last 12 months, please explain the reasons or criteria you used to select the specific ranking(s) or list(s) that you used.

4. In general, what do you think are the potential advantages or benefits of using journal rankings and journal quality lists?

5. In general, what do you think are the potential disadvantages, drawbacks or dangers of using journal rankings and journal quality lists?

6. Do you have any advice for someone who wants to use a journal ranking or journal quality list?

7. In general, are you in favour or against journal rankings and journal quality lists? Please explain your answer. 